Conclusion This findings of this study supports the use of PESI scoring systems in predicting early mortality. Study data suggests that sPESI has non-inferior predictive properties compared to the PESI, and therefore may prove of higher utility in day-to-day clinical practice. These tools may be reliably used to consider outpatient management of patients with PE, which includes imaging up to 72 hours after A\&E attendance.

\begin{tabular}{|c|c|c|c|c|c|}
\hline & Day 1 & Day 3 & Day 7 & Day 30 & Day 90 \\
\hline \multicolumn{6}{|l|}{ PESI } \\
\hline Class I (\%) & $0(0)$ & $0(0)$ & $0(0)$ & $0(0)$ & $0(0)$ \\
\hline Class II (\%) & $0(0)$ & $0(0)$ & $1(1.8)$ & $1(1.8)$ & $2(3.5)$ \\
\hline $\begin{array}{l}\text { Class III } \\
(\%)\end{array}$ & $0(0)$ & $0(0)$ & $0(0)$ & $0(0)$ & $0(0)$ \\
\hline $\begin{array}{l}\text { Class IV } \\
(\%)\end{array}$ & $0(0)$ & $0(0)$ & $2(4.3)$ & $3(6.4)$ & $5(10.6)$ \\
\hline Class V (\%) & $1(1.8)$ & $3(5.3)$ & $\begin{array}{l}7 \\
(12.3)\end{array}$ & $\begin{array}{l}14 \\
(24.6)\end{array}$ & $\begin{array}{l}15 \\
(26.3)\end{array}$ \\
\hline $\begin{array}{l}p \text { value } \\
\text { sPESI }\end{array}$ & 0.735 & 0.024 & 0.001 & $<0.001$ & $<0.001$ \\
\hline Low risk & $0(0)$ & $0(0)$ & $0(0)$ & $0(0)$ & $0(0)$ \\
\hline High risk & $1(0.5)$ & $3(1.6)$ & $\begin{array}{l}10 \\
(3.5)\end{array}$ & $18(9.7)$ & $\begin{array}{l}22 \\
(11.8)\end{array}$ \\
\hline $\begin{array}{l}p \text { value } \\
\text { PESI }\end{array}$ & 0.648 & 0.271 & 0.012 & $<0.001$ & $<0.001$ \\
\hline $\begin{array}{l}\text { AUROC } \\
\text { sPESI }\end{array}$ & 0.9 & 0.9 & 0.82 & 0.86 & 0.84 \\
\hline AUROC & 0.9 & 0.89 & 0.86 & 0.9 & 0.88 \\
\hline
\end{tabular}

\section{P175 BURDEN OF CEREBRAL INFARCTS IDENTIFIED BY SCREENING CEREBRAL MRI SCANS IN PATIENTS WITH PULMONARY ARTERIOVENOUS MALFORMATIONS}

${ }^{1} \mathrm{G}$ Fatania, ${ }^{1} \mathrm{M}$ Patel, ${ }^{1} \mathrm{JE}$ Jackson, ${ }^{2} \mathrm{CL}$ Shovlin. ${ }^{1}$ Imperial College Healthcare NHS Trust, London, UK; ${ }^{2}$ Imperial College London, London, UK

\subsection{6/thoraxjnl-2017-210983.317}

Introduction In a recent UK study, 61/497 (12.3\%) of consecutive patients with pulmonary arteriovenous malformations (PAVMs) had experienced a clinical ischaemic stroke at median 46 (range 16-82) years. ${ }^{1}$ Conventional stroke management included antiplatelet agents, but since many PAVM patients have underlying hereditary haemorrhagic telangiectasia (HHT), there has not been a blanket recommendation to treat all PAVM patients with such agents if residual PAVMs remain after maximal treatment. The goal of this study was to evaluate evidence of silent ischemia in patients with PAVMs.

Methods Between 20/04/2009 and 02/12/2016, 43 individuals (20 males; 23 females) with known or suspected HHT underwent a cerebral MRI scan performed for the purpose of HHT cerebral AVM screening. All available scans were analysed by two independent neuroradiologists, blinded to patient demographics/PAVM status. Data were subsequently categorised and analysed using STATA IC v13 (Statacorp, Texas).

Results Patient ages ranged from 17-74 (mean 42.2) years. Twenty-two $(51.1 \%)$ were known to have PAVMs demonstrable by thoracic CT scan, and 21 had PAVMs excluded by CT scan. There was no age difference between the PAVM and
non-PAVM cohorts (mean 43.3 [range 16-73] versus 41 [2165] years respectively, $\mathrm{p}=0.46)$. No scan demonstrated a cerebral AVM, none provided evidence of prior cerebral haemorrhage, but only $22(51.2 \%)$ of scans were reported as normal. $17(81 \%)$ of patients without PAVMs had a normal scan, compared to $5(22.7 \%)$ PAVM patients $(\mathrm{p}=0.0002) .15 / 21$ (68.2\%) PAVM patients had at least one infarct, and 6/21 $(27.3 \%)$ had microangiopathic changes. The mean number of infarcts per PAVM patient was 1.58 compared to 0.14 in non-PAVM patients $(\mathrm{p}<0.0001)$. Intriguingly, while the rates of anterior circulation territory infarcts did not differ between PAVM and non-PAVM groups (patient means 0.36 and 0.14 , $\mathrm{p}=0.18$ ), the PAVM patients had more infarcts in posterior circulation territories (means 1.21 and $0, \mathrm{p}<0.0001$ ).

Conclusions The findings identify high rates of silent cerebral ischaemic changes in patients with PAVMs, and raise the question whether all patients with persistent PAVMs after treatment should have pharmacological stroke prevention therapy, in the absence of a clinical stroke.

\section{REFERENCE}

1. Shovlin et al. PLOS One 2014, Feb 19;9(2):e88812.

\section{P176 INVESTIGATING ENVIRONMENTAL FACTORS ASSOCIATED WITH CEREBRAL ABSCESSES IN PATIENTS WITH PULMONARY ARTERIOVENOUS MALFORMATIONS VIA AN INTERNATIONAL ONLINE QUESTIONNAIRE}

${ }^{1} \mathrm{EJ}$ Boother, ${ }^{1} \mathrm{SC}$ von Widekind, ${ }^{2} \mathrm{CL}$ Shovlin. ${ }^{1}$ Imperial College School of Medicine, London, UK; ${ }^{2}$ Imperial College London, London, UK

\subsection{6/thoraxjnl-2017-210983.318}

Introduction and objectives Patients with pulmonary arteriovenous malformations (PAVMs) are at high risk of cerebral abscess with life-changing morbidity and mortality. These patients often concurrently have hereditary haemorrhagic telangiectasia (HHT). A recent study of patients with PAVMs/ HHT at a single institution suggested several environmental associations with cerebral abscess, particularly dental care, higher iron intake, and long-haul flights. ${ }^{1}$ For example, 4/37 $(10.8 \%)$ cerebral abscess patients reported their abscess occurred after long-distance travel.

Methods In order to capture data on wider exposure of this population to such risk factors, an online questionnaire was developed using Survey Monkey. In total, 139 non-biassed questions gathered data online about an individual's HHT and/or PAVM phenotype, and environmental factors of relevance to cerebral abscess and other study foci in our group. With ethical approval (16/LO/1909), participants were recruited following advertisement through global HHT support networks.

Results The survey opened on 31 st May 2017. Within 7 weeks, 449 patients with self-reported HHT had completed the questionnaire. The majority $(\geq 60 \%)$ were North Americans, with Europeans constituting the second largest group. 229 (51\%) had PAVMs, usually diagnosed in their twenties to fifties. 89/229 (38.9\%) had been treated by PAVM embolization and $13(5.7 \%)$ by surgery. $17(7.42 \%)$ had experienced a cerebral abscess and 46 gave a family history of cerebral abscess. Preliminary analysis of long-distance travel data revealed most patients rarely travelled for $\geq 3$ hours. 266 participants reported the number of flights they had taken in their lifetime of durations $<4$ hours, $4-8$ hours and $\geq 8$ hours. 
In total, an estimated 27,722 hours were flown giving a mean average of 122 hours, i.e., approximately 10 long-distance flights per lifetime.

Conclusions This survey provides a large dataset from individuals with PAVMs/HHT, captured without a bias toward flight usage as in flight-specific surveys. The data suggest long-distance travel is less common than previously thought for the HHT population, which adds greater weight to the previously published association[1] between long-distance travel and cerebral abscess risk. This approach should enable the development of better tools to predict and reduce the risk of cerebral abscess for these patients.

\section{REFERENCE}

1. Boother et al. Clin Infect Dis 2017, Apr 19. doi:10.1093/cid/cix373

\section{P177 COMPUTED TOMOGRAPHY DIAGNOSTIC MODEL FOR DIAGNOSIS OF PULMONARY HYPERTENSION}

AJ Switt, M Chin, B Currie, CA Elliot, A Charalampopolous, S Rajaram, JM Wild, C Johns, DG Kiely. University of Sheffield, Sheffield, UK

10.1136/thoraxjnl-2017-210983.319

Introduction Pulmonary hypertension $(\mathrm{PH})$ is severe cardiorespiratory condition associated with poor prognosis with diagnosis reliant on invasive right heart catheterization (RHC). Several measurements on computed tomography (CT) have been shown to have diagnostic value in $\mathrm{PH}$, however few studies have attempted to identify the added value of combining CT metrics for the diagnosis of $\mathrm{PH}$.

The aim of this study is to develop a composite diagnostic CT model for patients with suspected PH.

Methods Patients with suspected PH who underwent CT and RHC were identified. Standard axial and reconstructed images were used to derive CT metrics of cardiac and pulmonary vasculature anatomy. A derivation and validation cohort were randomly constructed to derive and test a binary logistic regression model of $\mathrm{PH}$. Receiver operating characteristic (ROC) analysis assessed the diagnostic value of the model and individual metrics.

Results 491 patients were identified (derivation cohort $\mathrm{n}=247$ and validation $\mathrm{n}=244$ ). Main pulmonary arterial (MPA) diameter, right ventricular outflow tract (RVOT) thickness, right ventricular muscle area and interventricular septal (IVS) angle variables correlated strongest to mean pulmonary arterial pressure, $r=0.458 \quad(p<0.001), \quad r=0.441 \quad(p<0.001)$, $\mathrm{r}=0.481(\mathrm{p}<0.001)$ and $\mathrm{r}=0.622(\mathrm{p}<0.001)$, respectively. The diagnostic regression model included RVOT, IVS angle, MPA diameter, LV size and the interlobar artery to bronchus ratio. The area under the curve from ROC analysis was 0.931 $(p=<0.001)$ in the derivation cohort and a 0.938 $(p=<0.001)$ value in the validation cohort, more accurate the individual CT metrics $(\mathrm{p}<0.05)$. A highly sensitive threshold of 0 units had a sensitivity of $95 \%$ and specificity of $50 \%$ and a highly specific threshold of 3.3 units had sensitivity of $69 \%$ and specificity of $100 \%$.

Conclusion A multivariate diagnostic model derived from axial CT images is accurate in suspected PH. The identified highly sensitive and specific thresholds may help in both patient screening and in selection for referral to specialist centres.

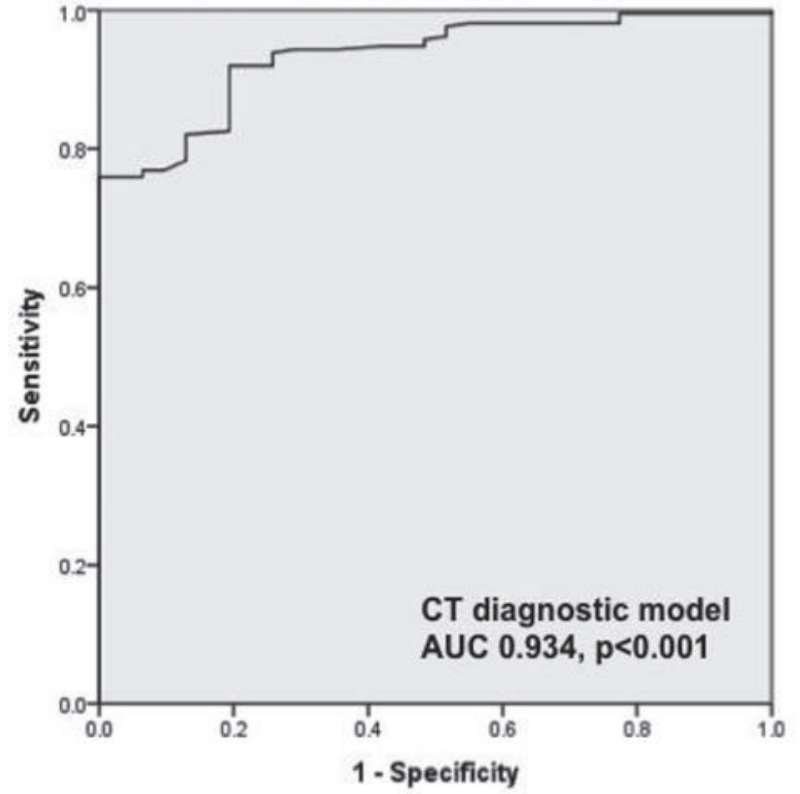

Abstract P177 Figure 1 ROC curve showing the performance of model 2 in the validation cohort with all included variables.

\section{P178 5 YEAR FOLLOW UP OF PATIENTS INVESTIGATED FOR SUSPECTED PE. WHAT FURTHER TESTS FOR SUSPECTED VTE ARE PERFORMED AND ARE THEY POSITIVE?}

${ }^{1} \mathrm{~J}$ Henderson, ${ }^{1} \mathrm{~S}$ Hainey, ${ }^{1} \mathrm{M}$ Avery, ${ }^{2} \mathrm{NCD}$ Morley, ${ }^{2} \mathrm{KC}$ Muir, ${ }^{2} \mathrm{EJR}$ van Beek, ${ }^{2} \mathrm{JT}$ Murchison. ${ }^{1}$ University of Edinburgh, Edinburgh, UK; ${ }^{2}$ Clinical Research Imaging Centre, Edinburgh, UK

\subsection{6/thoraxjnl-2017-210983.320}

The diagnosis of a Pulmonary Embolism (PE) is a challenging clinical problem, our approach to which has changed greatly since the introduction of Computed tomographic pulmonary angiography (CTPA). CTPA is now established as the imaging modality of choice for the diagnosis of PE, however there are concerns that CTPA causes the over-diagnosis of clinically irrelevant $\mathrm{PE},{ }^{1,2}$ and there is little data concerning the outcomes and further imaging following a CTPA at long followup times. Here we present long term follow-up of CTPAs over 5 years, looking at further imaging related to suspected thromboembolic disease after more than 2000 studies. After their initial CTPA, further studies were documented retrospectively using electronic patient records. Figure 1 demonstrates what further imaging for suspected venous thromboembolic event (VTE) patients had following their CTPAs scans over 5 years. In a one-year period, $24 \%$ of the negative studies, $38 \%$ of the positive, and $50 \%$ of the indeterminate studies had repeat testing for suspected thromboembolic disease. Indeterminate studies received repeat testing faster $(p<0.001)$, and those with negative studies received fewer repeat tests $(p<0$. 001). Those with a positive initial result were more likely to have positive recurrent testing over the whole 5 year period, and these data also suggest a trend showing increased risk with positive PEs rather than other VTEs. Furthermore, although CTPAs had a very high calculated negative predictive value for excluding PE (over 99\%), many patients went on to have repeat testing following a negative result. Understanding 